\title{
Improvement in Fetomaternal Outcomes and Cardiovascular Health in Gestational Diabetes Mellitus following a Short-course Yoga Therapy
}

\author{
Manoharan Renugasundari ${ }^{1}$, Gopal Krushna Pal ${ }^{1, *}$, Latha Chaturvedula ${ }^{2}$, Nivedita Nanda ${ }^{3}$, \\ KT Harichandrakumar ${ }^{4}$, Lakshmanan Vidyalakshmi ${ }^{5}$
}

\section{Manoharan \\ Renugasundari ${ }^{1}$, Gopal Krushna Pal ${ }^{1, *}$, Latha Chaturvedula ${ }^{2}$, Nivedita Nanda ${ }^{3}$, KT Harichandrakumar ${ }^{4}$, Lakshmanan Vidyalakshmi ${ }^{5}$} 'Department of Physiology, JIPMER, Puducherry, INDIA.

${ }^{2}$ Department of Obstetrics and Gynecology, JIPMER, Puducherry, INDIA. ${ }^{3}$ Department of Biochemistry, JIPMER, Puducherry, INDIA.

${ }^{4}$ Department of Biostatistics, JIPMER, Puducherry, INDIA.

${ }^{5}$ Department of Advance Centre for Yoga Therapy, Education and Research, JIPMER, Puducherry, INDIA.

\section{*Correspondence}

\section{Dr. Gopal Krushna Pal}

Senior Professor of Physiology, and Program Director, Advance Center of Yoga, Jawaharlal Institute of Postgraduate Medical Education and Research (JIPMER), Puducherry-605006, INDIA.

Phone: +919344291160

Email: drgkpal@gmail.com

\section{History}

- Submission Date: 21-01-2021

- Review completed: 02-03-2021;

- Accepted Date: 17-03-2021.

DOI : 10.5530/ijcep.2021.8.1.5

Article Available online

http://www.ijcep.org

\section{Copyright}

(C) 2021 Phcog.Net. This is an openaccess article distributed under the terms of the Creative Commons Attribution 4.0 International license.

\begin{abstract}
Background and Aim: Though the effects of yoga on fetomaternal outcomes in GDM have been assessed earlier, a complete cardiometabolic profile and fetomaternal outcomes have not been studied yet. Also, there is no report of practice of a short course yoga therapy administered prior to parturition in GDM patients. Therefore, in the present study, effects of a structured short-course yoga module on cardiometabolic risks, fetomaternal outcomes and psychophysical health in GDM were assessed. Methods: A total of 21 pregnant women diagnosed to have GDM, admitted to Obstetrics Ward of tertiary care hospital prior to their delivery were recruited for the study. Anthropometric indices such as height, weight and BMI were calculated. Cardiometabolic risk (CMR) parameters such as heart rate (HR), systolic blood pressure (SBP) and diastolic blood pressure (DBP) were recorded, and rate pressure product (RPP) was calculated. The psychophysical health was assessed by using two questionnaires such as Perceived Stress Scale (PSS) scoring and Quality of Life (QoL) scoring. The participants were provided yoga therapy consisting of basic asanas and slow pranayamas daily and the schedule continued till their delivery. Yoga therapy was administered for a minimum of seven days and maximum of ten days. All the parameters before and after yoga were compared. Correlation of RPP, the marker of myocardial work stress was done with various parameters to assess the association of stress and metabolic status with the cardiovascular (CV) risk. Results: There was a significant decrease $(P=0.000)$ in $B H R, S B P, D B P, R P P$ after yoga intervention when compared to the pre-yoga assessment. There was also a significant decrease $(P=0.001)$ in blood glucose after yoga intervention. The comparison of PSS and QoL before and after yoga intervention revealed a significant reduction in stress level $(P=0.000)$ and improvement in $\mathrm{QoL}(P=0.000)$ after yoga intervention. RPP was significantly correlated with PSS. Conclusion: Practice of yoga for about one week consisting of basic asanas and slow pranayama significantly decreases blood glucose and stress levels and improves fetomaternal outcomes in GDM patients. The myocardial work stress in GDM patients could be linked to the psychological stress in them. Key words: Gestational diabetes mellitus, Cardiometabolic risk, Fetomaternal outcome, Rate-pressure product, Yoga, Pranayama.
\end{abstract}

\section{INTRODUCTION}

Gestational diabetes mellitus (GDM) is defined as abnormal carbohydrate tolerance with the onset or first detection during the present pregnancy at 24-28 weeks of gestation. ${ }^{[1]}$ GDM is one of the most common medical condition that complicates pregnancy. Prevalence of GDM ranges from $3.8 \%$ to $41 \%$ in various parts of India. In Tamil $\mathrm{Nadu}, \mathrm{GDM}$ was reported to be $18.9 \%$ in general population. ${ }^{[2]}$ Though GDM usually subsides with adequate treatment and following few months of delivery, the women with history of GDM have sevenfold increased risk of developing type 2 diabetes mellitus (T2DM) later in life and also they have high risk of developing cardiovascular disease (CVD) subsequently. ${ }^{[3,4]}$ Therefore, with increasing

prevalence of GDM, there is increase in prevalence of T2DM and CVD in women.

GDM has been reported to be associated with many maternal and fetal short-term and long-term adverse events. GDM women have fetus large for gestational age (macrosomia), which is due to enhanced growth effects of increased circulating insulin in the fetus, as insulin is a known somatic growth factor. ${ }^{[5,6]}$ Macrosomia in turn increases the risk of baby having shoulder dystocia and usually causes vaginal tear to the mother. Therefore, in GDM, lower segmental caesarean section may become a necessity rather than the spontaneous vaginal delivery. Those who deliver vaginally, invariably experience prolonged labor, more labor pain and maternal exertion, which

Cite this article: Renugasundari M, Pal GK, Chaturvedula L, Nanda N, Harichandrakumar KT, Vidyalakshmi L. Improvement in Fetomaternal Outcomes and Cardiovascular Health in Gestational Diabetes Mellitus following a Short-course Yoga Therapy. Int J Clin Exp Physiol. 2021;8(1):17-21. 
could be due to decreased myometrial tonicity and contraction in addition to increased size of the fetus.

Clinically and metabolically, GDM resembles T2DM. The hallmark feature of GDM is insulin resistance. Insulin resistance in GDM is usually due to pancreatic $\beta$ cell dysfunction, in which $\beta$ cells of islets fail to acclimatize to the growing demands of insulin during pregnancy. Many hormones such as estrogen, cortisol, human placental lactogen which are called as diabetogenic placental hormones hinders the action of insulin on binding of insulin to its receptor in the later part of pregnancy. ${ }^{[7]}$ The interference by prodiabetogenic hormones could be at the level of post-insulin-receptor cell signaling pathway. As insulin promotes the entry of glucose uptake into cells through GLUT4, insulin resistance prevents entry of glucose into cells. ${ }^{[8,9]}$ This results in hyperglycemia which mimics T2DM. It could be also that the levels of prodiabetogenic placental hormones increase in GDM.As metabolically GDM is similar to T2DM, the cardiometabolic risk profile in GDM may possibly also be close to the diabetes mellitus. The cardiometabolic risks in GDM could be due to many factors such as genetic and epigenetic modifications, inflammation, endothelial dysfunction, metabolic syndrome and lifestyle changes. ${ }^{[10]}$ There are reports of increased stress level due to poor fetomaternal outcome in GDM patients, which might affect their future quality of life. However, once diagnosed to have GDM, there are possibilities of increase in stress due to the general perception of poor gestational and delivery outcomes associated with the disease. However, till date, cardiometabolic risks and psychophysical health have not been assessed in GDM patients.

Due to socioeconomic factors, pregnant women in India usually visit antenatal clinic in the last trimester of pregnancy, especially few weeks prior to delivery. Therefore, mild GDM usually remain undetected in Indian women. Those who come for antenatal check-ups early in pregnancy also do not follow the treatment schedule sincerely. India being the capital of diabetes and progression of GDM to T2DM further increases the percentage of diabetes, and GDM per se is associated with fetomaternal morbidities and mortalities, therapeutic intervention becomes necessary in GDM. Pregnancy being a special situation and GDM as such being a high-risk pregnancy, non-pharmacological therapy will be of more value in the management of GDM. Practice of yoga, especially slow pranayama has been reported by us to decrease cardiometabolic risks. ${ }^{[11-13]}$ We have also reported improvement in cardiometabolic functions in women having risks of PIH. ${ }^{[14]}$ Though the effects of yoga on fetomaternal outcomes in GDM have been assessed earlier in two studies, ${ }^{[15,16]}$ a complete cardiometabolic profile and fetomaternal outcomes have not been studied yet. Till date, there is no report of practice of a short course yoga therapy administered in the later weeks of gestation prior to delivery in GDM patients. Therefore, the present study was undertaken with the objective of assessment of the effect of a structured short-course yoga module on cardiometabolic risks, fetomaternal outcomes and psychophysical health in GDM.

\section{MATERIALS AND METHODS}

After obtaining approval from Scientific Advisory Committee and Institute Ethics Committee of Jawaharlal Institute of Postgraduate Medical education and Research (JIPMER), Puducherry, India, 21 pregnant women diagnosed to have GDM, admitted to Obstetrics Ward of JIPMER hospital were recruited for the study. Written informed consent was obtained from all the participants. The study was registered as clinical trial in Clinical Trial Registry of India (CTRI/2020/06/025807). As there is no previous report of effects of short course of one two weeks practice of yoga on cardiometabolic risk and fetomaternal outcome, the present study was conducted as a preliminary study, and a convenient sample size of 21 was considered for the study.

\section{Inclusion and Exclusion Criteria}

GDM women receiving insulin and/or oral anti-diabetic agents were included in the study. GDM women with severe anemia, polyhydramnios, multiple pregnancy, pregnancy induced hypertension, cardiac problems, GDM women with previous history of PCOS on metformin treatment and Body mass index (BMI) $>35 \mathrm{Kg} / \mathrm{m}^{2}$ were excluded from the study.

\section{Parameters Assessed}

Anthropometric indices such as height and weight were measured and BMI was calculated. Cardiometabolic risk (CMR) parameters such as heart rate (HR), systolic blood pressure (SBP), diastolic blood pressure (DBP) were recorded using automated blood pressure monitor (Omron automatic blood pressure monitor HEM-8712, Omron Healthcare Company Ltd, Tokyo, Japan) and rate pressure product (RPP) was calculated. The glycemic status (fasting blood glucose) was noted from their case records. The psychophysical health was assessed by using two questionnaires such as Perceived Stress Scale (PSS) scoring and Quality of Life (QoL) scoring. All the GDM patients were followed after delivery for assessment of fetomaternal outcomes.

\section{Intervention}

The participants were provided yoga therapy (yoga module is given in Table 1) daily from their admission to Obstetrics Ward of JIPMER hospital at the later part of $3^{\text {rd }}$ trimester i.e. at $35^{\text {th }}$ or $36^{\text {th }}$ weeks of gestation and it continued till their delivery. Yoga therapy was administered for a minimum of seven days and maximum of ten days. They were given daily yoga therapy at their bedside in the obstetrics ward under supervision of a certified yoga instructor of advance Centre for Yoga Therapy, Education and Research (ACYTER) of JIPMER, Puducherry. Therefore, there was no dropout in the study.

All the above-mentioned parameters such as anthropometric indices, cardiometabolic risk parameters and psychophysical health scores were assessed before and after 10 days of yoga intervention. The participants were followed up till $48 \mathrm{hr}$ of delivery to assess the fetomaternal and neonatal outcomes.

\section{Statistical Analysis of Data}

Statistical analysis was done using SPSS version 17 software (Chicago, IL, USA). Data were analyzed by Kolmogrov-Smirnoff test for normality. All the data were expressed as mean and SD. Comparison between pre yoga intervention and post yoga intervention was done by Paired $t$ test for parametric data and by Wilcoxon Signed Rank test for non-parametric

Table 1: Schedule of yoga intervention.

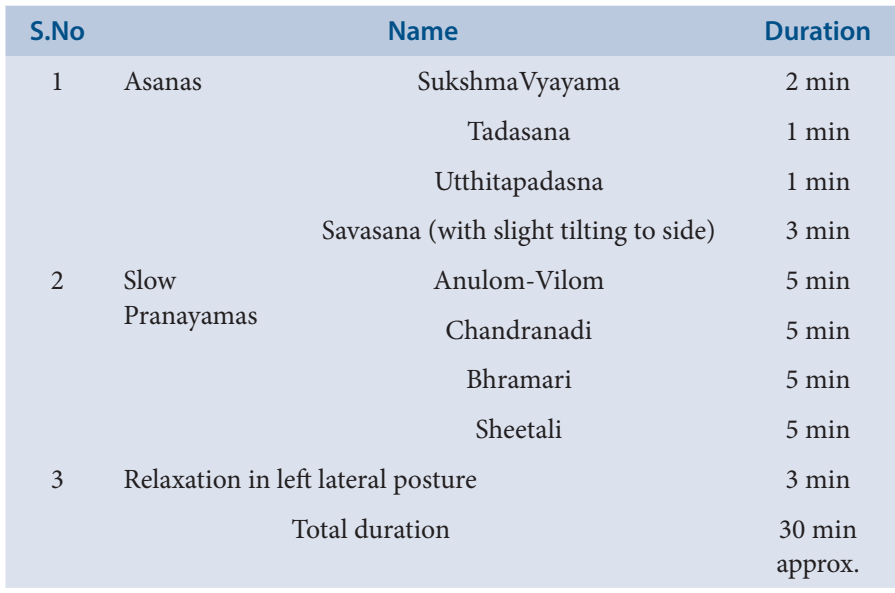


data. Pearson correlation was to determine the association of RPP with various parameters.

\section{RESULTS}

Table 2 shows the comparison of cardiovascular parameters and blood glucose in GDM women before and after yoga intervention. There was a significant decrease $(\mathrm{P}=0.000)$ in $\mathrm{BHR}, \mathrm{SBP}, \mathrm{DBP}, \mathrm{RPP}$ after yoga intervention when compared to the basal assessment. There was also a significant decrease $(\mathrm{P}=0.001)$ in blood glucose after yoga intervention.

Table 3 depicts the comparison of PSS and QoL before and after yoga intervention. There was a significant reduction in stress level $(\mathrm{P}=0.000)$ and improvement in $\mathrm{QoL}(\mathrm{P}=0.000)$ after yoga intervention which was statistically significant.

Table 4 displays that 5 (23.80\%) of GDM women delivered before 36 weeks of gestation and 16 patients $(76.19 \%)$ delivered between 36 to 40 weeks of gestation. 12 (57.14\%) GDM women underwent spontaneous vaginal delivery and $3(14.28 \%)$ patients had instrumental delivery and 6 patients (28.58\%) underwent lower segment caesarean section. Among 21 patients, 17 GDM women $(80.96 \%)$ had no pregnancy complications. Table 5 shows that among 21 fetus of GDM women, 16 fetus $(76.19 \%)$ had no complications. 18 neonates $(85.72 \%)$ scored $\geq 7$ in the APGAR score at $1^{\text {st }}$ min and all the 21 neonates $(100 \%)$ scored $\geq 7$ at the $5^{\text {th }}$ min. 5 neonates $(23.81 \%)$ were less than $2.5 \mathrm{Kg}$ in the birth weight, 14 neonates (66.67\%) had birth weight between $2.5-3.4 \mathrm{Kg}$ and 2 neonates $(9.52 \%)$ had birth weight more than $3.5 \mathrm{Kg}$. Among 21 neonates, 18 neonates $(85.72 \%)$ were not admitted in NICU after birth.

Table 6 demonstrates the correlation analysis of RPP with various parameters before and after yoga intervention. There was positive correlation of PSS $(r=0.43, \mathrm{P}=0.049)$ with RPP before yoga intervention.

\begin{tabular}{|c|c|c|c|}
\hline Parameters & $\begin{array}{c}\text { Pre- } \\
\text { intervention } \\
(n=21)\end{array}$ & $\begin{array}{l}\text { Post- } \\
\text { intervention } \\
(n=21)\end{array}$ & $\mathbf{P}$ \\
\hline Age (years) & $29.14 \pm 4.88$ & ........ & NA \\
\hline BMI $\left(\mathrm{Kg} / \mathrm{m}^{2}\right)$ & $27.94 \pm 2.79$ & & \\
\hline BHR (per min) & $92.38 \pm 6.96$ & $86.48 \pm 6.31$ & 0.000 \\
\hline SBP $(\mathrm{mmHg})$ & $121.62 \pm 11.08$ & $115.29 \pm 9.81$ & 0.000 \\
\hline DBP (mmHg) & $81.86 \pm 7.96$ & $78.10 \pm 7.80$ & 0.000 \\
\hline$\underset{\mathrm{min})}{\mathrm{RPP}(\mathrm{mmHg} /}$ & $113.01 \pm 14.65$ & $100.96 \pm 11.81$ & 0.000 \\
\hline $\begin{array}{c}\text { Blood glucose } \\
(\mathbf{m g} \%)\end{array}$ & $134.29 \pm 24.06$ & $113.38 \pm 21.53$ & 0.001 \\
\hline
\end{tabular}

Data was expressed as mean \pm SD. P value less than 0.05 was considered to be statistically significant. BHR: Basal heart rate; SBP: Systolic blood pressure; DBP: Diastolic blood pressure; RPP: Rate pressure product.

Table 3: Comparison of stress scale and quality of life before and after yoga intervention.

\begin{tabular}{llll}
\multicolumn{1}{c}{ Parameters } & $\begin{array}{c}\text { Pre-intervention } \\
(\mathbf{n}=21)\end{array}$ & $\begin{array}{c}\text { Post-intervention } \\
(\mathbf{n}=21)\end{array}$ & P \\
PSS & $22.81 \pm 4.78$ & $17.48 \pm 4.61$ & 0.000 \\
QoL & $86.81 \pm 7.88$ & $97.48 \pm 7.72$ & 0.000
\end{tabular}

Data was expressed as mean \pm SD. P value less than 0.05 was considered to be statistically significant. PSS: Perceived stress scale; QoL: Quality of life.
Table 4: Assessment of maternal outcomes.

\begin{tabular}{ccc}
\hline Parameters & $\mathbf{n}$ & Percentage \\
\hline Gestational weeks at delivery & & \\
Less than 36 weeks of gestation & 5 & 23.81 \\
36 to 40 weeks of gestation & 16 & 76.19 \\
Mode of delivery & & \\
Spontaneous vaginal delivery & 12 & 57.14 \\
Instrumental delivery & 3 & 14.28 \\
Lower segmental caesarean section & 6 & 28.58 \\
Pregnancy complications & & \\
Abruption & 1 & 4.76 \\
Premature rupture of membrane & 3 & 14.28 \\
No complications & 17 & 80.96
\end{tabular}

Table 5: Assessment of fetal and neonatal outcomes.

\begin{tabular}{|c|c|c|}
\hline Parameters & $\mathrm{n}$ & Percentage \\
\hline \multicolumn{3}{|l|}{ Fetal outcomes } \\
\hline Fetal macrosomia & 0 & 0 \\
\hline Low birth weight & 5 & 23.81 \\
\hline No complications & 16 & 76.19 \\
\hline \multicolumn{3}{|l|}{ Neonatal outcomes } \\
\hline \multicolumn{3}{|c|}{ APGAR score at $1^{\text {st }} \mathrm{min}$} \\
\hline$<7$ & 3 & 14.28 \\
\hline$\geq 7$ & 18 & 85.72 \\
\hline \multicolumn{3}{|c|}{ APGAR score at $5^{\text {th }} \mathrm{min}$} \\
\hline$\geq 7$ & 21 & 100 \\
\hline \multicolumn{3}{|l|}{ Birth weight } \\
\hline$<2.5 \mathrm{Kg}$ & 5 & 23.81 \\
\hline $2.5-3.4 \mathrm{Kg}$ & 14 & 66.67 \\
\hline$\geq 3.5 \mathrm{Kg}$ & 2 & 9.52 \\
\hline \multicolumn{3}{|l|}{ NICU admission } \\
\hline Yes & 3 & 14.28 \\
\hline No & 18 & 85.72 \\
\hline
\end{tabular}

Table 6: Pearson correlation analysis of RPP with various parameters in women having GDM ( $n=21)$ before (pre) and after (post) yoga intervention.

\begin{tabular}{ccccc|} 
Parameters & \multicolumn{2}{c}{ Pre-intervention } & \multicolumn{2}{c|}{ Post-intervention } \\
& $r$ & $\mathrm{P}$ & $r$ & $\mathrm{P}$ \\
Glucose & 0.145 & 0.533 & -0.132 & 0.587 \\
PSS & 0.438 & 0.049 & 0.486 & 0.041 \\
QoL & -0.232 & 0.312 & -0.138 & 0.582
\end{tabular}

$P$ value less than 0.05 was considered to be statistically significant. $r$ : Regression coefficient; RPP: Rate pressure product; PSS: Perceived stress scale; QoL: Quality of life. 
Also, there was positive correlation of PSS $(r=0.48, \mathrm{P}=0.041)$ with RPP after yoga intervention.

\section{DISCUSSION}

In the present study, five to ten days practice of short course of yoga therapy resulted in significant decrease in blood glucose level (Table 2) prior to the delivery in GDM women admitted to a tertiary hospital. There was also substantial decrease in heart rate, blood pressure and RPP. RPP is a measure of myocardial oxygen demand and a physiological indicator myocardial work stress. ${ }^{[17]}$ Increase in RPP is a marker of CV risk and decrease in RPP reflects decreased risk. ${ }^{[18]}$ Thus, significant decrease in blood glucose and RPP indicates decreased cardiometabolic risk following short course practice of yoga in GDM patients. There was also significant decrease in PSS and QoL following yoga practice (Table 3), indicating that the short course of yoga therapy was adequate to reduce the level of stress and improve the quality of life in these patients. Further, RPP was significantly correlated with PSS before and practice of yoga (Table 6). These findings indicate that myocardial work stress in GDM patients, which was more before practice of yoga was linked to the higher level of psychological stress; and decrease in RPP in these patients could be linked to decreased PSS following yoga practice. The present study is the first to report the effects of practice of yoga for a shorter period of about five days to improve blood glucose and to decrease psychophysical stress in women with GDM just prior to their delivery.In the present study, about $57 \%$ of women had normal delivery, $76 \%$ had completed their term of 36 to 40 weeks of gestation and there were no complications of pregnancy in about $81 \%$ of cases (Table 4 ). The previous data from JIPMER hospital indicate more than $70 \%$ of caesarian delivery, early occurrence of delivery (before $36^{\text {th }}$ week) and incidence of complications of delivery, in more than $50 \%$ of GDM women. Thus, it appears that a short course practice of yoga schedule for 5 to 10 days may facilitate normal delivery in GDM. Further, there was no fetal complications in more than $70 \%$ and APGAR score was more than 7 in $85 \%$ newborns. Thus, fetal and newborn outcomes were very encouraging following short course practice of yoga practice. Of course, it can't be claimed that practice of yoga for about a week could result in decrease in body size of the fetus, and improvement in maternal and neonatal outcomes. But it can be presumed that improvement in fetomaternal outcomes could be due to improved cardiometabolic functions and improvement in the functions of the birth passage of women with GDM, as practice of yoga is known to strengthen the tone of the muscles and ligaments of pelvic floor in pregnant women and promote the process of parturition. ${ }^{[19]}$ However, in the present study, with decrease in RPP following yoga practice in GDM women, there could have been increase in maternal cardiac functions and dynamics of circulation, which might have subsequently resulted in increase in adequate delivery of oxygen to the fetus, consequently leading to improved fetal metabolism and functions. Significant decrease in blood glucose in GDM patients following one week practice of yoga under direct supervision is a novel finding of the present study, which indicates that even in the later stage of pregnancy practice of yoga for few days could be immensely helpful in reducing metabolic stress in these high-risk pregnant women. As such, a schedule of longer duration practice of yoga is not well complied by women population in India due to heavy socio-cultural responsibilities in the family. Therefore, a thoroughly supervised yoga therapy for a shorter duration under strict expert supervision as adopted in the present study will be more acceptable and meaningful in the management of GDM and delivery in GDM. The type of yoga therapy delivered to the patients were very basic and simple asanas, slow pranayama's and relaxation in left lateral posture that a pregnant woman can perform in the $35^{\text {th }}-40^{\text {th }}$ week of gestation. In the present study, all the participants had performed yoga procedure exceptionally well as they were performed under complete supervision, at the bed side of the patient. These basic asanas, especially the utthitapadasana are known to strengthen the pelvic floor and facilitate smooth parturition. ${ }^{[19]}$ The practice of slow pranayama's is known to reduce $\mathrm{CV}$ risk and improve glycemic control in diabetic patients ${ }^{[20]}$ and GDM patients. ${ }^{[15,16]}$ However, the impact of the yoga schedule adopted in the present study with combination of vary basic asanas and four slow pranayamas has not been practiced and assessed before. Though Balaji, et al. have reported improvement in metabolic, maternal and fetal parameters following practice of asanas and pranayama the yoga schedule, ${ }^{[15]}$ that study design was different from the present study and the timing and duration of interventions were also different.

Many studies have reported the beneficial effect of the practice of yoga on diabetes, confirming that the practice of yogasana can stimulate the insulin producing cells in the pancreas and by increase insulin sensitivity that lowers blood sugar level. ${ }^{[20,21]}$ Although the effect of yoga on maternal and neonatal outcome variables has not been studied more in pregnancy, several studies have looked at these variables. Available evidence like Rakhshani, et al. reported that yoga can potentially be an effective therapy in reducing the complications of pregnancy and improving fetal outcomes. ${ }^{[22]}$ Narendran $S$ and others performed studies to assess the efficacy of yoga on pregnancy outcome and concluded that an integrated approach to yoga during pregnancy is safe to both mother and fetus. ${ }^{[23,24]}$ Yoga improves birth weight, decreases preterm labor, and decreases IUGR either in isolation or associated with PIH, without complications. ${ }^{[25]}$

Yoga also enhances the sense of well-being and decreases the level of stress. ${ }^{[26]}$ Thus, the practice of yoga in the present study resulted in decrease in stress and improvement in quality of life. Thus, to treat GDM, decrease stress, improve feto-neonatal outcomes, the antenatal mother should practice asanas along with pranayama's, especially in developing countries, where the antenatal health care delivery system is poorly practiced and implemented. Pregnancy affects both the maternal and fetal metabolism and even in non-diabetic women it exerts a diabetogenic effect. Therefore, in general all pregnant women should practice yoga to prevent the occurrence of GDM. We conclude that the antenatal mother with GDM if practice yoga even for a period of one week, there will be reduction in $\mathrm{CV}$ risks and complications of GDM, improvement in psychological health and quality of life, and improvement in maternal and fetal outcomes in GDM. The entire yoga therapy conducted under direct supervision is the merit of the study.

\section{Limitations of the Study}

There was no control group of GDM women without practice of yoga to compare with the women who practiced yoga. The sample size was less.

\section{CONCLUSION}

Practice of yoga for about one week consisting of basic asanas and slow pranayama significantly decreases blood glucose level and stress level and prevents adverse maternal and fetal outcomes in GDM patients. The myocardial work stress in GDM patients could be linked to their psychological stress.

\section{ACKNOWLEDGEMENT}

We acknowledge the financial support given by JIPMER Authority to the first author as part of her PhD Intramural grant, for conduct of this study.

\section{CONFLICT OF INTEREST}

The authors declare that they have no conflict of interest. 


\section{ABBREVIATIONS}

CMR: Cardiometabolic Risk; HR: Heart Rate, SBP: Systolic Blood Pressure; DBP: Diastolic Blood Pressure; RPP: Rate Pressure Product; PSS: Perceived Stress Scale; QoL: Quality of Life; GDM: Gestational Diabetes Mellitus; T2DM: Type 2 Diabetes Mellitus.

\section{REFERENCES}

1. American Diabetes Association. Gestational Diabetes Mellitus. Diab Care 2003;26(Suppl.1):S103-5.

2. Chudasama RK, Kadri AM, Ratnu A, Jain M, Kamariya CP. Magnitude of gestational diabetes mellitus, its influencing factors and diagnostic accuracy of capillary blood testing for its detection at a Tertiary Care Centre, Rajkot, Gujarat. Indian J Community Med. 2019;44(2):142-6.

3. Zhu Y, Zhang C. Prevalence of gestational diabetes and risk of progression to type 2 diabetes: A global perspective. Curr Diab Rep. 2016;16(1):7.

4. Madhu SV. Diabetes in pregnancy-a critical window of opportunity. Int $J$ Diabetes Dev. 2018;38:1-3.

5. Coustan DR. Pharmacological management of gestational diabetes: An overview. Diab Care. 2007;30(Suppl 2):S206-8

6. Hod M, Merlob P, Friedman S, Schoenfeld A, Ovadia J. Gestational diabetes mellitus. A survey of perinatal complications in the 1980s. Diabetes. 1991;40(Suppl 2):74-8.

7. Catalano PM, Tyzbir ED, Roman NM, Amini SB, Sims EA. Longitudinal changes in insulin release and insulin resistance in nonobese pregnant women. Am J Obstet Gynecol. 1991:165(6):1667-72.

8. Plows JF, Stanley JL, Baker PN, Reynolds CM, Vickers MH. The pathophysiology of gestational diabetes mellitus. Int J Mol Sci. 2018;19(11):3342.

9. Alejandro EU, Mamerto TP, Chung G, Villavieja A, Gaus NL, Morgan E, et al. Gestational diabetes mellitus: A harbinger of the vicious cycle of diabetes. Int J Mol Sci. 2020;1-21.

10. Seshiah V, Balaji V, Balaji MS, Paneerselvam A, Kapur A. Pregnancy and diabetes scenario around the world: India. Int J Gynaecol Obstet. 2009;104(Suppl 1):S35-

11. Pal GK, Habeebullah S, Pal P, Subha M, Saranya K, Nanda N. Practice of Alternatenostril breathing (Anuloma-viloma pranayama) attenuates the development of hypertension and cardiometabolic dysfunctions during pregnancy in women having risk factors for pregnancy-induced hypertension. Int J Clin Exp Physiol. 2018;5(4):189-95.

12. Hari KB, Pal P, Pal GK, Balachander J, Jayasettiaseelon E, Sreekanth S, et al. Effect of yoga therapy on heart rate, blood pressure and cardiac autonomic function in heart failure. J Clin Diagnos Res. 2014;8(1):14-6.

13. Pal GK, Agarwal A, Karthik $S$, Pal P, Nanda N. Slow yogic breathing through right and left nostril influences sympathovagal balance, heart rate variability, and cardiovascular risks in young adults. North Am J Med Sci. 2014;6(3):145-51.

14. Pal GK, Habeebullah S, Pal P, Subha M, Saranya K, Nanda N. Practice of alternatenostril breathing (Anuloma-viloma Pranayama) attenuates the development of hypertension and cardiometabolic dysfunctions during pregnancy in women having risk factors for pregnancy-induced hypertension. Int J ClinExp Physiol. 2018;5(4):189-95

15. Balaji PA, Varne SR. Physiological effects of yogasanas and pranayama on metabolic parameters, maternal and fetal outcome in gestational diabetes. Nat J Physiol Pharm Pharmacol. 2017;7(7):724-8

16. Abirami $P$, Judie $A$. Integrated approach of yoga therapy on maternal and fetal outcome in gestational diabetes mellitus. Int J Pharmaceut Clin Res. 2015;7(6):377-82.

17. Meena $R$, Pal P, Papa D, Pal GK. Increased rate pressure product is linked to sympathovagal imbalance in Indian obese postmenopausal women. Int J Clin Exp Physiol. 2018;5(1):39-43.

18. Pal GK, Pal P, Indumathy J, Suchitra B, Sirisha A. Decreased rate pressure product by yoga therapy in the first-degree relatives of type 2 diabetics is linked to the decrease in body mass index. Int J Clin Exp Physiol. 2016;3(1):45-7.

19. Narendran S, Nagarathna R, Nagendra HR. In: Yoga for Pregnancy. $2^{\text {nd }}$ Edn. Assell Illustrated. London; 2008;120-9.

20. Keerthi GS, Pal P, Pal GK, Sahoo JP, Sridhar MG, Balachander J. Effect of 12 weeks of yoga therapy on quality of life and Indian diabetes risk score in normotensive Indian young adult prediabetics and diabetics: Randomized control trial. J Clin Diagnos Res. 2017;11(9):CC10-4.

21. Balaji PA, Varne SR, Ali SS. Effects of yoga - Pranayama practices on metabolic parameters and anthropometry in type 2 diabetes. Int Multidiscip Res J. $2011 ; 1(10): 1-4$

22. Rakhshani A, Nagarathna $R$, Mhaskar R, Mhaskar A Thomas A Gunasheela $S$. The effects of yoga in prevention of pregnancy complications in high-risk pregnancies: A randomized controlled trial. Prev Med. 2012;55(4):333-40.

23. Jiang $Q$, Wu Z, Zhou L, Dunlop J, Chen P. Effects of yoga intervention during pregnancy: A review for current status. Am J Perinatol. 2015;32(6):503-14.

24. Narendran S, Nagarathna R, Narendran V, Gunasheela S, Nagendra HR. Efficacy of yoga on pregnancy outcome. J Altern Complement Med. 2005;11(2):237-44

25. Field T, Diego M, Hernandez-Reif M, Medina L, Delgado J, Hernandez A. Yoga and massage therapy reduce prenatal depression and prematurity. J Body Mov Ther. 2012;16(2):204-9.

26. Naik GS, Gaur GS, Pal GK. Effect of modified slow breathing exercise on perceived stress and basal cardiovascular parameters. Int J Yoga. 2018;11(1):53

Cite this article: Renugasundari M, Pal GK, Chaturvedula L, Nanda N, Harichandrakumar KT, Vidyalakshmi L. Improvement in Fetomaternal Outcomes and Cardiovascular Health in Gestational Diabetes Mellitus following a Short-course Yoga Therapy. Int J Clin Exp Physiol. 2021;8(1):17-21. 